This is a post refereeing version of a paper published as:

\title{
The subversion of Mill and the ultimate aim of nursing
}

Snelling, PC (2018). The subversion of Mill and the ultimate aim of nursing. Nursing Philosophy. e12201.https://doi.org/10.1111/nup.12201

The published version is available here:

\begin{abstract}
This is lightly edited and referenced version of a presentation given at the $20^{\text {th }}$ International Philosophy of Nursing conference in Quebec on $23^{\text {rd }}$ August 2016.

Philosophical texts are not given the same prominence in nurse education as their more valued younger sibling, primary research evidence, but they can influence practice through guidelines, codes and espoused values. John Stuart Mill's harm principle, found in On Liberty, is not a universal law, and only a thoroughgoing libertarian would defend it as such, though it, or its remnants, can be seen can be seen in policy documents. But its influence is weakening. Smoking bans in enclosed spaces were initially justified with other-regarding considerations, but judgements from unsuccessful legal challenges from patients in UK psychiatric hospitals rely on preventing harm to the smoker, even when smoking outside, which does not harm others. In the wake of legislation, no-smoking policies enacted by hospitals are becoming more aggressive, banning smoking both inside and outside, and extending the use of power gained through employment to prevent nurses assisting patients enjoy a lawful habit. Mill's dictum has been subverted, and this speaks to the fundamental purpose of nursing. Should nurses collude and willingly exert their power for their version of the good of the patient? Or should they instead reaffirm values that support and facilitate life choices made by autonomous people? The paper supports the latter option, and this has wider application for nursing which can be illuminated, if not settled, by revisiting Mill and his famous dictum.
\end{abstract}

Key Words John Stuart Mill, no smoking policy, Rampton, Smoking, On Liberty

Dr Paul Snelling

Principal Lecturer in adult nursing

Department of Nursing and Midwifery

University of Worcester

Henwick Grove

Worcester

WR2 6AJ

용 01905542615

p.snelling@worc.ac.uk 


\section{Introduction}

When thinking about how I could make best use of this kind invitation to speak, I recalled a conference (I won't say which) some years ago. Two plenary speakers stick in the memory. The first was a well-known nurse academic, who gave every impression that he was speaking completely off the cuff. He was to the extent that there were no notes and plenty of animation, but it soon became apparent that this was because it was little more than an introductory lecture, probably delivered in the same way to lecture halls full of bemused first semester undergraduates every September for many years. I went to coffee wondering whether he was worth the airfare.

The second was a distinguished philosopher, and her paper was so dense and detailed that it passed straight over my head into the ether. Unlike the first speaker she was reading her paper aloud. But it was a paper written to be read, not listened to. The complex ideas needed pause, a re-read and thoughtful application, and because, as the education literature tells us we have limited concentration spans, not least in a crowded and warm conference hall, her ideas were quickly lost. In my presentation, I aimed to steer the middle ground between these positions. I don't think that I said much that you haven't already heard but it's good to pause and revisit Mill and ask if we can learn from how application of his thought is evolving. This paper is more of an extended editorial than an original contribution.

At the conference, I read the presentation, though I wrote it to be listened to. But 'just' reading comes at price, something that Mill knew well. His home education consisted in large measure of discussions with his father, including reading aloud the works of the ancient Greeks, answering questions when asked. A passage from Mill's autobiography illustrates a difficulty and a more important point to come. Mill senior paid a great deal of attention to elocution, perhaps at the expense of understanding, and this

[...] made this reading aloud to him a most painful task. Of all the things he required me to do, there was none which I did so constantly ill, or in which he perpetually lost his temper with me. He had thought much on the principles of the art of reading, especially the most neglected part of it, the inflexions of the voice or modulation as writers on elocution call it [...] and had reduced it to rules, grounded on the logical analysis of a sentence. These rules he strongly impressed on me, and took me severely to task for every violation of them: but I even then remarked (though I did not venture to make the remark to him) that though he reproached me when I read a sentence ill and told me how I ought to have read it, he never, by reading it himself, shewed me how it ought to be read. A defect running through his admirable modes of instruction, as it did through all his modes of thought, was that of trusting too much to the intelligibleness of the abstract, when not embodied in the concrete.

(Mill, 1989, p. 39-40 emphasis in original)

Mill Senior was a theorist it seems, but his genius child appreciated the value of practical application. The relationship between theory and practice is a recurring theme and this quotation is equally apt for conference presentations and more generally for nursing and nursing education. I want to consider briefly how and if detailed analyses of, and adherence to historical philosophical texts can be of use to practicing nurses before speaking a little about Mill's famous harm principle and how it is being subverted, and I will illustrate this with some legal cases and policies. Finally, I will suggest that how nurses understand the limits of Mill's work tells us a great deal about the fundamental purpose of nursing - 
travelling, unlike Mill Senior, from practice to theory. I admit and apologise that the analysis is in a UK context, but the issues are international, and comparison would be very interesting.

\section{Evidence and Philosophy - unequal siblings}

The use of evidence has been part of nursing practice for some time now, though of course it is challenged and questioned, including recently in a book edited by Martin Lipscomb (Lipscomb, 2016). Simply, what is supposed to happen is something like this: Primary evidence, often research evidence, is located and appraised, and in many cases this evidence is used to produce guidance which informs but does not dictate practice. There are other factors of course and these can operate at many levels. At the guideline level, this might include financial considerations or organisational values.

Other factors might affect an individual decision made by an individual nurse, but if she ventures outside the guideline, she will need to provide justification. This is very familiar for nurse educators, many of whom spend a good portion of their working lives helping students to understand the steps in the process. The relevant point is that individual nurses are not exhorted or expected, they are required to be proficient in understanding evidence, and that is why we spend so much time teaching it. Preregistration students are not required to undertake original research but as well as following guidelines, they must be able to arrive at a view about whether the guideline is worth following, and they must be able to find primary research, appraise it, and draw upon it in their practice. Now, as the chapters in Lipscomb's book show, this is far from being the whole story, but these requirements are there in regulatory and educational documents. You can point at them. ${ }^{1}$

How would it look if we replaced evidence with philosophy, the thing that examines the values, which I alluded to? The field is vast, but considering moral philosophy alone, an analogous system would require that nurses engage with primary texts and/or ideas, appraise them and use them to justify decisions. Of course that doesn't happen. I'm not saying that nurses are not allowed to do this, or that none do, I am saying that they aren't required to. Instead, guidelines, in the form of codes of ethics or conduct are produced, and despite their inadequacy (Snelling, 2016a, 2017), this seems to be enough. The standards for competence in the UK state that 'All nurses must practice with confidence according to The Code, and within other recognised ethical and legal frameworks' (NMC, 2015, p.13). We can point at legal frameworks, but what is meant by recognised ethical frameworks, and recognised by whom? One framework seen in official documents ${ }^{2}$ is the ubiquitous four principles (Beauchamp \& Childress, 2013). I'm possibly in a minority when I say that I think that this approach is a useful place to start. It probably counts as a 'recognised' framework, but one of its chief claimed advantages, which is also used as a critique, is that you do not have to go to philosophy and philosophical texts to understand it and use it. You understand that you should (or must) promote autonomy but not why you should (Clouser \& Gert 1990). In that regard, philosophy is evidence's poor relation.

\footnotetext{
${ }^{1}$ In the UK, the Nursing and Midwifery Council standards of competence for registered nurses state that 'all nurses must: appreciate the value of evidence in practice, be able to understand and appraise research, apply relevant theory and research findings to their work, and identify areas for further investigation' (NMC, 2015, p.6). These standards were initially published a standards for education but were later extended so that they apply to all registered nurses.

${ }^{2}$ For example, the National Institute of Health and Clinical Excellence in the UK is the organisation which evaluates effectiveness and cost-effectiveness of treatments and produces clinical guidelines. Their document Social Value Judgements: Principles for the development of NICE guidance, uses the four principles in its analyses (NICE 2008).
} 
When we talked about returning to the philosophers at this conference, what did we mean, exactly? We probably didn't mean that we can require our students or practicing nurses to return to them. Do we expect writers-of-codes to return to them, or refer to them? Possibly this is the case for ethics-code writers in Canada and the US, but it certainly is not for the conduct-code writers in the UK. The two types of codes differ significantly (Snelling, 2016a). Personally, I return to original texts to refresh my teaching and thinking, but it has to be said that referring to them is not always popular with students, and in a packed curriculum with limited assessments, examination of primary philosophical texts is not seen as important.

The distinction of going from theory to practice or from practice to theory is important here. The first of these probably requires detailed knowledge of philosophy. I am in the other camp; I certainly do not consider myself a philosopher. I go to philosophy probably superficially and widely to illuminate specific problems and issues connected with my practice, and I would encourage others to do the same. Partly this refers to the process I alluded to earlier, of getting philosophy into practice. Partly it is determined by understanding that contemporary application of the work and values of philosophers is far from easy.

James Sterba starts his book, the Triumph of Practice over Theory in Ethics (Sterba, 2005) by noting modern critiques of Aristotle's slaves, Kant's racism and Mill's colonialism, but these three long-dead men continue to influence health care and nursing ethics and practice. It's not so much the detailed interpretation and application of sacred texts that is important as the broad thrust of ideas contained within. The concept 'compassion', central to nursing practice, illustrates this. Aristotle's notion of compassion, ${ }^{3}$ elaborated upon by Martha Nussbaum (1996), includes the criterion that compassion be deserved, that some people therefore are not worthy recipients of a compassionate response. This is at odds to modern nursing application, which requires nurses to show compassion to everyone. I say requires here because this is what you see in codes, including the sorts of codes that are more like law than ethics (Snelling, 2016a). What I'm taking from this is that looking to the philosophers in great detail and then trying to apply their texts directly to practice is not likely to be helpful for most practicing nurses. Times change. So what I'm going to do is suggest some areas of nursing practice that might be guided by John Stuart Mill's thought, or at least some of the many issues that he illuminated, and try to use them in practical application. This is not a detailed analysis and I will not be trusting to the intelligibleness of the abstract.

\section{What would Mill say about smoking policies?}

For the rest of the paper I will be discussing smoking. I'm not a smoker myself, though I was one. I'm not an apologist for it and I'd be disappointed to discover that one of my children had started. But I think that smoking is an interesting subject to discuss for a number of reasons. First, from the perspective of orthodox health care it is seen as a virtually undisputed bad thing - and this extends also to business practices of tobacco companies. Second, because things change rapidly; it wasn't so long ago that doctors' and nurses' images were advertising cigarettes (Gardner \& Brandt, 2006), and we have seen over the last 60 years or so how research has identified the link between smoking and ill health and continues to influence policy. Third, smoking policy requires thought about so many important issues including the nature of agency and decision making, understanding what is meant by health and how it differs from wellbeing, and the nature of toleration. How these and other issues relate to smoking can be seen as bellwethers for health care policy and more importantly for us, for nursing practice.

\footnotetext{
${ }^{3}$ Translated as pity - it is discussed, briefly, in the Art of Rhetoric (Aristotle, 2004)
} 
As almost all student public health essays include, the standard position against paternalism is that of John Stuart Mill in On Liberty, which has become known (though not by him) as the 'harm principle':

[T] he only purpose for which power can be rightfully exercised over any member of a civilised community, against his will, is to prevent harm to others. His own good, either physical or moral is not a sufficient warrant

(Mill, 1991, p.10-11)

Mill's famous claim underpins other more nuanced and developed positions, for example that taken by Joel Feinberg:

It is always a good reason in support of penal legislation that it would probably be effective in preventing (eliminating, reducing) harm to persons other than the actor (the one prohibited from acting)...

(Feinberg, 1984, p.26).

Mill is not talking about 'just' criminal prohibition, as is Feinberg in this passage. His proscription can be taken to include power exercised by any institution, and Mill also included the tyranny of 'prevailing opinion and feeling'. His remarks about the tyranny of society seem remarkably prescient applied to a Facebook generation and the public shaming that we read about in our newspapers and on line:

Society can and does execute its own mandates: and if it issues wrong mandates instead of right, or any mandates at all in things with which it ought not to meddle, it practices a social tyranny more formidable than many kinds of political oppression, since, though not usually upheld by such extreme penalties, it leaves fewer means of escape, penetrating much more deeply into the details of life, and enslaving the soul itself.

(Mill, 1991, p.8-9)

I'm not saying that the harm principle is or should be absolute, regardless of what Mill would say about this (Jennings, 2009, Powers et al., 2012). Both Canada and the UK have criminalised riding on a motorcycle without a helmet, ${ }^{4}$ and this can be understood as against the principle. But the harm principle, or its remnants, does appear in official policy documentation in the UK:

[...] the Government will balance the freedoms of individuals and organisations with the need to avoid serious harm to others. We will look carefully at the strength of the case before deciding to intervene and to what extent. This must be based on a rigorous assessment of the evidence about health and wider harms, with the potential benefits balanced against the social and economic costs to individuals, organisations and wider society.

(DH, 2010a, p.28).

This is from a summary of evidence that accompanied the government policy document, Healthy Lives, Healthy People (DH, 2010b). The frustrated lawyer in me immediately spies

\footnotetext{
${ }^{4}$ The picture is more complex in the US, where individual states decide the law. Three states have no law, and it has been proposed that the liberty of being allowed to ride without a helmet should incur a tax, which would cover the cost to the State of any injury caused. This might protect others' interests while protecting liberty (Nolte et al., 2017).
} 
the word serious as in 'serious harms'. I'm of the view that this word means something, or rather that it should mean something and if this is the case then this statement seems to be saying something important about the calculations it claims to use in justification. It might be considered that the word 'serious' further extends the liberties which Mill was at pains to protect. As we shall see, it is much more likely simply to be careless drafting. ${ }^{5}$

In 2004 the tiny Himalayan country of Bhutan became the only country to criminalise tobacco sale and use, but the ban was ineffective largely because of a flourishing black market, and was rescinded in 2009. Though the World Health Organisation considers legislation 'to be at the heart of effective tobacco control' (Blanke \& da Costa e Silva, 2004, p.15) it is rarely argued that tobacco be banned outright. ${ }^{6}$ Other measures like banning advertising and plain packaging may restrict commercial liberty, and though this might upset thoroughgoing libertarians, it does not directly threaten the liberty of individuals in any meaningful sense. Increased taxation is known to reduce demand (for example, Nesson, $2017)^{7}$ and in some cases, where income is low, this may be taken to amount to direct prohibition. Mill has some interesting things to say about this:

A further question is, whether the State, while it permits should nevertheless indirectly discourage conduct which it deems contrary to the best interests of the agent; whether, for example, it should take measures to render the means of drunkenness more costly... On this as most practical questions, many distinctions require to be made. To tax stimulants for the sole purpose of making them more difficult to be obtained, is a measure differing only in degree from their entire prohibition: and would be justified only if that were justifiable.

(Mill, 1991, p.111)

The conclusion here seems clear: The measure is different only in degree, and since prohibition for the person's own good is not justifiable, neither is taxation. But he goes on:

Every increase in cost is a prohibition, to those whose means do not come up to the augmented price; and to those who do, it is a penalty laid on them for gratifying a particular taste. Their choice of pleasure and their mode of expending their income, after satisfying their legal or moral obligations to the State and to individuals are their own concern and must rest with their own judgement. These considerations may seem at first sight to condemn the selection of stimulants as special subjects of taxation for the purpose of revenue. But it must be remembered that taxation for fiscal purposes is absolutely inevitable...It is hence the duty of the state to consider in the imposition of taxes which commodities the consumers can best spare: and...to select in preference those of which it deems the use, beyond a very moderate quantity, to be positively injurious. Taxation, therefore, of stimulants up to the point which produces the largest amount of revenue is not only admissible but to be approved of.

(Mill, 1991, p.111)

\footnotetext{
${ }^{5}$ There's also confusion about this word in respect to breaking a confidence, where some regulatory documents require disclosure to prevent harm, and others require the prevention of serious harm (Snelling, 2017).

${ }^{6}$ Though see MacDaniel et al. (2015) for a review of the 'tobacco endgame'

${ }^{7}$ The same arguments are applied to other 'bad' things including minimum price per alcohol unit, and 'sugar tax'.
} 
There are a number of parallels to contemporary smoking debates but two are worthy of note First is the matter of intention. Mill is saying that taxation is acceptable, laudable even, when its function is to raise money, but not acceptable if its function is to reduce demand. The problem here is that these issues can be conflated. The World Health Organization (2015) very clearly says that increased price is a measure used to reduce demand, as do governments (Ekpu \& Brown, 2015). This is against Mill. But it has also been suggested that these taxation policies represent a 'liberal egalitarian' approach to holding people responsible for their health-effecting behaviour, addressing, to varying degrees, the cost of treatment required (Cappelen \& Norheim, 2005). I don't think that Mill would have a problem with that.

The second and perhaps more important consideration here is the statement that people should be free to spend their money, 'after satisfying their legal or moral obligations to the State and to individuals'. The link between law and morality is too complex to discuss in detail here but the relationship need not be unpicked too far. I'm not going to be able to spend much time talking about Mill's view of morality, and it has been noted that there can be tension between his two most famous works, On Liberty and Utilitarianism. His point is an interesting one because the precise nature of our obligations to individuals are not clear. My own view is that a decision to continue to smoke or drink is a moral choice, which requires consideration of the effect our potentially diminished physical health has on those who have a legitimate interest in it (Snelling, 2014), and I'm with Mill in saying that financial obligations also require consideration. This obligation has to be undertaken in the context of our own life and own version of the good life and need not be demanding. Mill was scathing about the effects that our habits have on others if these diminish our ability to fulfil our obligations to them, but was clear that the wrongness was here, and not on the habit itself. Additionally, there is always difficulty in measuring and weighing the effects these habits have on other people and for what reasons. Mill's society did not have the benefit of universal welfare and health care, and so sickness and poverty had, in many cases, a more direct effect on dependents. ${ }^{8}$

While contemporary application of the harm principle is not absolute and therefore involves distinction and judgments, it nevertheless it is important in liberal countries. Or so it is claimed. Application is not so clear-cut now as it might have been in Mill's day, where the State's public health role was minimal. Today there is conflation of justifications where the principle is circumvented, with the purpose of pretending that it is largely intact. What I propose to do now is to introduce the legal case of the Rampton smokers and argue that that this shows that Mill has been deliberately subverted, and that this legal case has emboldened hospitals to do the same. Following that I'll discuss what all this means for nursing practice.

\section{The Rampton Smokers.}

In the UK from 1st July 2007, smoking was no longer permitted in enclosed or substantially enclosed public places and places of work. This legislative prohibition is allowed under Mill's dictum as it is other-regarding, or at least its stated justification was, for example by the House of Commons Health Committee (2005, para 41): 'The justification for the principle of a ban is straightforward: workers have a right to be protected from second hand smoke.' Exemptions allowed smoking in designated rooms in certain categories of places including

\footnotetext{
${ }^{8}$ Today, the economic cost of obesity and smoking is prominent in policy documents, but the figures often fail to account for savings to the State due to early death (Tovey, 2017).
} 
care homes, hospices and prisons (though prisons are now implementing no smoking policies ${ }^{9}$ ). Mental health units were afforded temporary exemption.

Smoking outside was permitted under law and though Trust policy permitted smoking outside in 'very rare cases', this could not be allowed at Rampton, which is a high security hospital, ${ }^{10}$ as smokers were prohibited by security considerations from going outside. Or so it was accepted. A number of cases were brought and referred to the Court of Appeal. The appellants claimed that the European Convention on Human Rights (ECHR) had been breached. Article 8 (Right to respect for private life) states that: ${ }^{11}$

1. Everyone has the right to respect for his private and family life, his home and his correspondence.

2. There shall be no interference by a public authority with the exercise of this right except such as is in accordance with the law and is necessary in a democratic society in the interests of national security, public safety or the economic well-being of the country, for the prevention of disorder or crime, for the protection of health or morals, or for the protection of the rights and freedoms of others.

Clearly, Article 8 does not simply mean that individuals are always allowed to do exactly as they wish in their homes, and whilst accepting that Rampton was the appellants' home, arguments were presented about the precise nature of the home and the nature of the act (smoking). The majority conclusion was 'Article 8 does not protect a right to smoke in Rampton'. ${ }^{12}$ The judgements are complex and long, and this is not a full commentary (and I am not a lawyer). Instead I'll present three areas of concern.

First, the relationship between the nature of a person's home and the nature of the act that he wishes to pursue in it is such that 'the less the appellant can rely upon the nature of the place in which the activity is pursued, the more he must rely on the proximity of the activity to his personal identity or physical and moral integrity.' ${ }^{13}$ The court is saying that a decision made by someone who really, really likes smoking and sees it central to their life is different from someone who isn't that bothered. The importance of an activity to a person, and therefore the value of protecting it is an individual matter, different between people. But having said that, the personal details of the appellants are not noted in the judgement, and do not appear to have been considered. Instead it is noted that 'Difficult as it is to judge the importance of smoking to the integrity of a person's identity, it is not in our view, sufficiently close to qualify as an activity meriting protection under article $8 .{ }^{14}$ So an individual's right to decide is itself decided not on capacity, as it is elsewhere in health care practice, but instead on a value judgment about the nature of a lawful activity.

\footnotetext{
${ }^{9}$ Currently, prisoners can smoke in their cells, but stated policy is to move to completely smoke free prisons, implemented in stages (Woodall \& Tattersfield, 2017).

${ }^{10}$ The comparison between prisons and mental health units have proved irresistible to those who wish to ban smoking, perhaps more so where mental health patients in secure units have committed crimes. See Thomas \& Richmond (2017) for arguments in favour of a ban.

${ }^{11}$ The UK voted to leave the European Union on $23^{\text {rd }}$ June 2016, and Article 50 of the Lisbon Treaty, giving a maximum notice of two years to leave was invoked on $29^{\text {th }}$ March 2017.

${ }^{12} \mathrm{R}(\mathrm{N}) \mathrm{v}$ The Secretary of State for Health. [2009] EWCA Civ 795. Paragraph 51.

${ }^{13} \mathrm{R}(\mathrm{N}) \mathrm{v}$ The Secretary of State for Health. [2009] EWCA Civ 795. Paragraph 49.

${ }^{14}$ (N) v The Secretary of State for Health. [2009] EWCA Civ 795. Paragraph 49.
} 
Second, the judgment noted that the duty of care held by hospitals towards its patients included a 'duty to take reasonable steps to prevent patients causing themselves self-harm.' ${ }^{15}$ A number of sources are cited in support of this, including, importantly, a regulation requiring that the 'Trust risk assess each patient against a range of factors including whether the patient presents a high risk of [...] (b) committing suicide or self-harming., 16

The judgement accepts that smoking is covered under this regulation, but there is no reason to believe that the regulation regards smoking as self-harm. The word "smoking" does not appear in the regulation or its guidance notes. Self-harm is a difficult concept not least because of the potential to include a vast range of behaviours, but it would be an idiosyncratic understanding of the term that includes smoking. Some authors do regard smoking as selfharm, but this is restricted to where it is considered 'excessive' (McAllister, 2003). Perhaps they mean that any smoking is excessive but it seems easy enough to draw a distinction between acute short-term harm from continual chain smoking, and the cumulative harm of an occasional habit. Interpreting the regulation cited to justify preventing smoking by regarding it as self-harm is an attempt to present it as irrational which would be considered overzealous if extended to other places. Under common law, I am justified in using reasonable force to disarm an individual to prevent him from cutting himself, but this does not extend to me snatching a cigarette from his lips and extinguishing it, along with a large chunk of his liberty, under the heel of my shoe.

Third and perhaps most important is the movement away from policy aims that echo Mill's justified restriction on liberty only to prevent harm to others, and towards the prevention of self-regarding harm, narrowly defined. Interference against an Article 8 right can be justified to protect the 'freedoms of others' but this other-regarding criterion is not needed to justify interference for the purpose of the protection of 'health or morals'. They stand alone. This can also clearly be seen in a second case brought by a Scottish smoker.

The claimant, a man with schizophrenia, had been detained for 18 years following low grade disorder offences for which he might have been imprisoned for a few months. In this case the EHCR was found to have been breached. In fact, Lord Stewart reached the decision with some reluctance:

Insofar as I have allowed the petitioner's application on the merits I have done so with a degree of reluctance. It is a perfectly reasonable proposition, given contemporary understanding about the effects of tobacco smoking, that patients in a hospital should not be permitted to smoke; and I have no cause to doubt that the respondents...have throughout been acting in what they genuinely see as the best interests of their patients. ${ }^{17}$

This can be read as directly against the Millian harm principle. However, he found for the claimant. In a sentence which seems destined to be much quoted he said that:

Article 8(2) ECHR authorises interventions which are "necessary in a democratic society [...] for the protection of health or morals": it is not a warrant for lifestyle fascism. ${ }^{18}$

Nevertheless, his judgement was overturned on appeal.

\footnotetext{
${ }^{15}$ (N) v The Secretary of State for Health. [2009] EWCA Civ 795. Paragraph 62.

${ }^{16}$ Paragraph 30 of the Safety and Security in Ashworth, Broadmoor and Rampton Hospital Directions 2000

${ }^{17}$ C M v The State Hospitals Board for Scotland. 2013 WL 4411375. Paragraph 5

${ }^{18}$ C M v The State Hospitals Board for Scotland. 2013 WL 4411375. Paragraph 52
} 


\section{Hospital No smoking policies.}

In these policies and judicial comments, we can see a move from prevention of harm to others towards prevention of harm to the smoker himself. Similar justification can be found in official guidance covering smoking in acute hospitals: 'Stopping smoking at any time has considerable health benefits for people using secondary care services' (NICE, 2013 p.6). There is a large amount of weak evidence detailed in the accompanying evidence document about impacts of bans on patients, for example, frequency of violent episodes and use of restraint in mental health units. But there cannot be direct evidence for the important policy provision that smoking should be prohibited in hospital grounds, because it is a normative question. It does not follow from a fact that smoking bans can be implemented that they should be. Considerably more time has been spent looking at the evidence than the values underpinning the policy, mirroring the asymmetry noted earlier in respect of nursing education standards. Evidence trumps philosophy.

In practice, general hospital bans can be quite aggressive. Here's one from Tameside Hospital. The first paragraph is firmly against Mill.

Smoking is a major cause of illness and early death and the government is taking active measures to decrease smoking behaviour by reducing the number of public areas in which smoking is permitted.

(Tameside Hospitals NHS Trust, 2016, para 1.1)

Staff responsibilities (including nurses) are made very clear further in the document.

Staff will not be permitted to assist patients who wish to smoke. Staff must not accompany patients who wish to smoke, and any member of staff who does so will be subject to disciplinary action in line with Trust policy (para 7.8)

If a patient leaves a Ward without permission from Ward staff, the patient will be wholly responsible for anything that may occur as a result of their action (para 7.9)

Not criminalisation, but power, directed at the patient through a caring and allegedly autonomous professional who knows the patient. ${ }^{19}$

So I have suggested that the legal judgements subvert Mill's principle in a number of ways, and that secure in the legal judgement, hospital no smoking policies do the same. In the final section, I will consider how nursing staff might regard these sorts of policies. First, there are questions of detail to address. It is not clear, for example, in the hospital policy, what 'assisting patients' consist of. Elsewhere in the policy it is stated that: 'All members of staff will be expected to reinforce the Trust's No Smoking Policy in circumstances which they are comfortable to do so' (para 7.5) and it is stated that staff should discourage patients from going outside (para 10.5). It does not say prevent - but nor could it as that would amount to false imprisonment. But it is very clear that no assistance should be given, and staff must not accompany patients or assist them. The Trust considers it more acceptable that, a lifelong smoker is at risk of falling rather than be helped to where he can enjoy a lawful activity, and if he falls, it is his own fault. ${ }^{20}$

The question I want to consider is whether a nurse should assist a patient who wants to smoke, legally, outside. But, a few caveats: First, in the UK, the government nursing

\footnotetext{
${ }^{19}$ For further discussion see Snelling (2016b)

${ }^{20}$ It's stated that 'The Trust's duty to provide reasonable care to the patient will not be affected', and I presume that this has been subjected to legal opinion.
} 
strategy emphasises, at tedious length, the '6 Cs': Care, Compassion, Competence Communication, Courage, Commitment (Cummings \& Bennett, 2012). The ' $C$ ' of critical thinking was not included, but the ' $\mathrm{C}$ ' of courage was. But for this exercise, I put to one side the fact that assisting the patient would put the individual's employment at risk. So we can recast the question as asking whether a nurse should want to assist. The second caveat concerns advocacy because I am aware that concepts of advocacy differ between north America and the UK. North American models of advocacy seem more advanced and also include an obligation to advocate more widely and at a higher level for social justice (Kagan et al., 2010, Lipscomb, 2011), and in relation to smoking policies, this could be argued both ways. So, we'll recast the question again so that it refers to advocating for an individual patient rather than advocating at the higher level of policy making. The question I think illustrates the fundamental purpose of nursing. A patient asks for your assistance in taking him out for a cigarette.

There are a couple of ways of arguing in favour of the ban, that is of refusing assistance, remembering that the harm principle (or something similar) is aligned to the principle of respecting autonomy. You can simply disregard the principle, which is what I've argued the legal case and identified policy does. Or you can say that in practice autonomy is valued but doesn't apply in this case. Motivations can be conflated and sophistry employed. But perhaps a softer defence of supporting the policy can be found within the psychology of nudging. Mill's case in On Liberty and more widely in his utilitarianism are based empirically on human nature (Skorupski, 2006). Practically, if we want to maximise something, happiness for example, we need to know what it is and to be confident that people know what makes them happy and can tell us. It is not based on what they ought to want. Similarly, the utilitarianism of much public health policy needs to have a view about the thing to be maximised and what this means. I tend to the view that a narrow biomedical view of health is adopted, but I cannot elaborate or defend that view here.

Putting aside the thorny issue of how addiction affects autonomous decision making, we have a great deal of research since Mill's time which shows us that we are not very good thinkers or decision makers, ${ }^{21}$ so that when we say that we want to smoke we might not mean it. We can simultaneously want to smoke and want to run the race which requires that we do not (Coggon, 2007). These insights about cognitive functioning can be seen in a range of places. They result in nudge techniques which apparently innocuously place salads before fries in works canteens (Thaler and Sunstein, 2008), but have also been used to defend a more stringent version of coercive paternalism (Conly, 2013). Mill's dictum has been undermined not so much in rhetoric, but in practice. Scholarship about nudging is progressing fast, and for a non-specialist, it can be difficult to keep up. There's little, so far, in the nursing literature and more is needed. It is not simply a matter of transferring the ethics of nudging from medicine or from policy-making, since nurses and nursing make special and specific claims about their relationships with patients and families, including a claim for advocacy and a claim for care over treatment. Both of these areas are challenged by nudging and the psychological insights which have fathered it. But, to be clear, the smoking bans discussed are not nudges; they are much more coercive that that, I simply make the point that a defence against the harm principle, (and respecting autonomy) along these lines seems plausible, but is not stated in any policy documents or legal judgements cited. Whatever the justification, I am claiming that a nurse defending a paternalist policy or declining to help a patient to have a

\footnotetext{
${ }^{21}$ This has many effects for nurses and nursing as discussed in the pages of this journal recently. (Paley, 2012, Miliken, 2017)
} 
cigarette should be able to base those judgements upon a detailed examination of motives and values.

Arguing against the ban in favour of assisting a patient seems to me to be a much simpler task. Return to Mill, and allow individuals to make up their own mind. When they have, advocate for them. It might not be the best thing for their physical health, narrowly understood, but who am I or you to judge how their life goes best for them?

Of course, this is a very simple version of a complex problem. The natures both of power and liberty differ between the agents in the chain that starts with the law, and progresses through guideline writers to employers and finally through nurses to patients. We can distinguish between different forms of liberty, as famously Isiah Berlin did. No-one is physically preventing a patient from getting off his bed and walking to a place where he can lawfully enjoy a cigarette without directly harming anyone else. Nurses are being forbidden from offering assistance to those who are unable to, being prevented from facilitating positive freedom:

I wish to be somebody, not nobody: a doer - deciding, not being decided for, selfdirected and not acted upon [...] that is of conceiving goals and policies of my own and realising them.

(Berlin, 1958, p.178).

The point about this dilemma is that you cannot hedge it. Admittedly, you could ask for more detail about a specific patient, and I could provide it. In discussion, that is often what people do, but some examples of policies say that there are no exceptions, or that there must be 'exceptional' circumstances, and these are decided upon by clinicians. Sooner or later you have to choose, and the way that you do tells you much about what you think the central function of nursing is. Is it to promote health at all costs, in which case defined how? Or is it to promote autonomous choice in health-effecting decisions. Both are stated values of the nursing profession internationally. Anyone joining me in the latter camp will recognise that this particular example does not stand alone. Committing to a view that nursing promotes and should promote - meaningful choice has implications for a wide range of areas of practice. For example, similar psychological insights about how we process numbers may help us present health information differently and in a way designed to help people make a choice rather than nudge, persuade, cajoule or coerce them into the choice already made for them. ${ }^{22}$ If, of course, that's what we want to do.

\section{Conclusion.}

I'll conclude with brief consideration of the possibility of disagreement. From a patient point of view, it seems to me that they are entitled to know what nurses are going to do for them or want to do for them. Are they going to help them smoke or not? A comparison between the nursing value that facilitates choice, and the one that believes in compassionate care is helpful here. Patients would feel rightly aggrieved if nurses acted on different compassionvalues, including one that could be defended by Aristotle that includes desert There may not be complete agreement on what compassion means and what it requires and how this can be promoted or enforced, but there is agreement, I think, about what it excludes. Should there be an attempt to settle the choice-value question? Whether we are with Mill or whether we collude in his subversion, and if we do, for what reason. Even if we see that smoking bans illustrate this question, and how it speaks so clearly to the fundamental purpose of nursing,

\footnotetext{
${ }^{22}$ See Gigereenzer (2015) for a discussion about understanding risk.
} 
debating it in detail identifies a number of further difficult practice-based issues, and these can be illuminated, if not settled, by revisiting Mill and his famous dictum. 


\section{References}

Aristotle (2004). The Art of Rhetoric. London: Penguin

Beauchamp, T.L., \& Childress, J.F. (2013) Principles of Biomedical Ethics $7^{\text {th }}$ edn. Oxford: Oxford University Press.

Berlin, I. (1958) Two concepts of liberty. In Berlin, I. (2013) Liberty. Oxford: Oxford University Press pp 166-217.

Blanke, D. \& da Costa e Silva, V. (2004). Tools for advancing tobacco control in the $21_{\text {st }}$ century. Tobacco control: an introductory guide. Geneva: World Health Organisation.

Cappelen, A.W., \& Norheim, O.F., (2005). 'Responsibility in health care: a liberal egalitarian approach', Journal of Medical Ethics. 31, 476-480.

Clouser, K.D. \& Gert, B. (1990) 'A critique of principlism', Journal of Medicine and Philosophy, 15(2), 219-236.

Coggon, J. (2007) Varied and principled understandings of autonomy in English law: justifiable inconsistency or blinkered moralism? Health Care Analysis, 15(3), 235255.

Conly, S. (2013) Against autonomy: justifying coercive paternalism. Cambridge: Cambridge University Press.

Cummings, J. \& Bennett, V. (2012). Compassion in Practice. Nursing, Midwifery and Care Staff. Our Vision and Strategy. NHS Commissioning Board. [on line] https://www.england.nhs.uk/wp-content/uploads/2012/12/compassion-in-practice.pdf (Accessed 5th September 2017).

Department of Health (2010a). Our Health and Wellbeing Today. London: Department of Health.

Department of Health (2010b). Healthy Lives, Healthy People. London: Department of Health.

Ekpu, V. U., \& Brown, A. K. (2015). The economic impact of smoking and of reducing smoking prevalence: review of evidence. Tobacco use insights, $8,1$.

Feinberg, J. (1984). The Moral limits of the Criminal Law. Volume 1: Harm to

Others. New York: Oxford University Press.

Gardner, M. N., \& Brandt, A. M. (2006). “The Doctors' Choice Is America's Choice” The Physician in US Cigarette Advertisements, 1930-1953. American Journal of Public Health, 96(2), 222-232.

Gigerenzer, G. (2015) Risk Savvy: How To Make Good Decisions. London: Allen Lane.

House of Commons Health Committee (2005). Smoking in public places: First report of session 2005 - 2006. London: The Stationary Office.

Jennings, B. (2009) Public health and Liberty: Beyond the Millian Paradigm. Public Health Ethics 2(2), 123-134 
Kagan P.N., Smith M.C., Cowling W.R. \& Chinn P.L. (2010) A nursing manifesto: an emancipator call for knowledge development, conscience, and praxis. Nursing Philosophy, 11(1), 67-84.

Lipscomb, M. (2011). Challenging the coherence of social justice as a shared nursing value. Nursing Philosophy, 12(1), 4-11.

Lipscomb, M. (ed) (2016) Exploring Evidence based Practice: Debates and Challenges in Nursing. London: Routledge.

McAllister, M. (2003). 'Multiple meanings of self harm: A critical review', International Journal of Mental Health Nursing, 12(3), pp. 177-185.

McDaniel, P. A., Smith, E. A., \& Malone, R. E. (2015). The tobacco endgame: a qualitative review and synthesis. Tobacco control, tobaccocontrol-2015.

Milliken A.(2017) Refining moral agency: Insights from moral psychology and moral philosophy. Nursing Philosophy.; e12185. https://doi.org/10.1111/nup.12185

Mill, J.S. (1873) Autobiography. London, Penguin 1989

Mill (1991) On Liberty and other essays. Oxford: Oxford University Press.

National Institute for Health and Clinical Excellence [NICE] (2008) Social Value

Judgements: principles for the development of NICE guidance. (2nd edn.),

London: National Institute for Health and Clinical Excellence. [on line]

https://www.nice.org.uk/Media/Default/About/what-we-do/Research-and-

development/Social-Value-Judgements-principles-for-the-development-of-NICEguidance.pdf (last accessed 5th September 2017)

National Institute for Health and Clinical Excellence (2013c) Smoking cessation

in secondary care: acute, maternity and mental health services. [on line] http://www.nice.org.uk/Guidance/ph48 (Accessed: 5th September 2017).

Nesson, E. (2017). Heterogeneity in Smokers' Responses to Tobacco Control Policies. Health economics, 26(2), 206-225.

Nolte, K. B., Healy, C., Rees, C. M., \& Sklar, D. (2017). Motorcycle policy and the public interest: a recommendation for a new type of partial motorcycle helmet law. The Journal of Law, Medicine \& Ethics, 45(1_suppl), 50-54.

Nursing and Midwifery Council (2015) Standards for competence for registered nurses. London: Nursing and Midwifery Council.

Nussbaum, M. (1996) Compassion: The basic social emotion. Social Philosophy and Policy, 13(1), 27-58.

Paley, J. (2012). Book review: The moral psychology handbook. Nursing Philosophy, 13, $80-83$

Powers, M., Faden, R., \& Saghai, Y (2012) Liberty, Mill and the framework of Public Health Ethics. Public Health Ethics, 5(1) 6-15 
Skorupski, J. (2006). Why Read Mill Today? London: Routledge.

Snelling, P. C. (2014). What's Wrong with Tombstoning and What Does This Tell Us About Responsibility for Health?. Public Health Ethics, 7(2), 144-157.

Snelling, P. C. (2016a). The metaethics of nursing codes of ethics and conduct. Nursing Philosophy, 17(4), 229-249.

Snelling, P. C. (2016b). Rounding on the Smokers: the myth of evidence based (nursing) policy. In Lipscomb, M. (ed) (2016) Exploring Evidence based Practice: Debates and Challenges in Nursing. London: Routledge, Chapter 15, pp 204-220.

Snelling, P. C. (2017). Can the revised UK code direct practice? Nursing ethics, 24 (4) 392407

Sterba, J.P. (2005). The triumph of practice over theory in ethics. New York: Oxford University Press.

Thaler, R. \& Sunstein, C. (2008). Nudge: Improving decisions about health wealth and happiness. London: Penguin Books.

Tameside Hospital NHSFT (2016) No smoking policy. [on line] http://www.tamesidehospital.nhs.uk/documents/NoSmokingPolicy.pdf (last accessed 5th September 2017)

Thomas, M., \& Richmond, R. (2017). Addressing the arguments against implementation of smoke-free policies in psychiatric facilities. Journal of Psychiatric and Mental Health Nursing, 24(5), 322-331.

Tovey, M (2017) Obesity and the public purse: weighing up the true cost to the taxpayer. London: Institute of Economic Affairs. [on line] https://iea.org.uk/wpcontent/uploads/2017/01/Obesity-and-the-Public-Purse-PDF.pdf (last accessed 5th September 2017)

Woodall, J., \& Tattersfield, A. (2017). Perspectives on implementing smoke-free prison policies in England and Wales. Health Promotion International. E access ahead of publication. doi: 10.1093/heapro/dax031.

World Health Organisation (2015). WHO Report on the Global Tobaccos Epidemic: Raising tax on tobacco. Geneva, World health Organisation 